\title{
Cost-Effectiveness Analysis of Simvastatin and Lovastatin/Extended- Release Niacin to Achieve LDL and HDL Goal Using NHANES Data
}

\author{
EDWARD P. ARMSTRONG, PharmD; WOODIE M. ZACHRY III, PhD; and DANIEL C. MALONE, PhD
}

\begin{abstract}
OBJECTIVE: The Third Report of the Expert Panel on Detection, Evaluation, and Treatment of High Blood Cholesterol in Adults, Adult Treatment Panel III (ATP III) encouraged reduced low-density lipoprotein (LDL) cholesterol levels for a greater number of patients and reemphasized the benefits of high-density lipoprotein (HDL) cholesterol. The purpose of this study was to compare 2 regimens achieving simultaneous LDL and HDL goals.

METHODS: A decision-analytic model compared the cost-effectiveness of simvastatin and lovastatin/extended-release niacin. The perspective of the analysis was that of a health system. Product labeling was used to determine changes in cholesterol concentrations and frequencies of clinically important adverse events. The Third National Health and Nutrition Examination Survey (NHANES III) adult data were used for baseline cholesterol levels. Each product was titrated to achieve LDL and HDL goals unless an adverse effect occurred. Direct medical costs were determined for each treatment to determine cost-effectiveness.
\end{abstract}

RESULTS: For both the $130 \mathrm{mg} / \mathrm{dL}$ and $100 \mathrm{mg} / \mathrm{dL}$ LDL goal analyses (and HDL $\geq 40 \mathrm{mg} / \mathrm{dL}$ ), lovastatin/extended-release niacin had higher success rates and lower estimated direct-medical costs than simvastatin. Simvastatin had the highest success rate in achieving LDL level $<160 \mathrm{mg} / \mathrm{dL}$ and $\mathrm{HDL} \geq 40 \mathrm{mg} / \mathrm{dL}$; however, its estimated direct-medical cost was approximately twice that of lovastatin/extended-release niacin (\$665 versus \$333).

CONCLUSION: For the LDL goals $<130 \mathrm{mg} / \mathrm{dL}$ and $<100 \mathrm{mg} / \mathrm{dL}$ (and HDL $\geq 40$ $\mathrm{mg} / \mathrm{dL}$ ) required of the majority of U.S. residents, lovastatin/extended-release niacin was both more successful and less costly than simvastatin.

KEYWORDS: Cholesterol, ATP III, LDL, HDL, Niacin, Lovastatin, Simvastatin

J Manag Care Pharm. 2004;10(3):251-258

\section{Authors}

EDWARD P. ARMSTRONG, PharmD, is associate professor, and DANIEL C. MALONE, PhD, is associate professor, Department of Pharmacy Practice and Science, Center for Health Outcomes and PharmacoEconomic Research, College of Pharmacy, University of Arizona, Tucson; WOODIE M. ZACHRY III, PhD, is an outcomes liaison, Eli Lilly and Company, Indianapolis, Indiana. (At the time of this study, Zachry was an assistant professor at the University of Arizona.)

AUTHOR CORRESPONDENCE: Edward P. Armstrong, PharmD, Associate Professor, College of Pharmacy, University of Arizona, Tucson, AZ 85721. Tel: (520) 626-5764; Fax: (520) 626-2023;

E-mail: armstrong@pharmacy.arizona.edu

Copyright $\odot$ 2004, Academy of Managed Care Pharmacy. All rights reserved.
$\mathrm{T}$ he treatment of dyslipidemia is of tremendous importance to patients, clinicians, and health systems. ${ }^{1-3}$ New cholesterol guidelines-the Third Report of the Expert Panel on Detection, Evaluation, and Treatment of High Blood Cholesterol in Adults, Adult Treatment Panel III (ATP III) have created treatment challenges by encouraging reduced lowdensity lipoprotein (LDL) cholesterol levels for a greater number of patients. ${ }^{4}$ These guidelines have also reemphasized that a low level of high-density lipoprotein (HDL) cholesterol is a major risk factor for coronary heart disease (CHD) events.

This recommendation is supported by the Veterans Affairs High-Density Lipoprotein Intervention Trial (VA-HIT) that was conducted to determine whether drug therapy to increase HDL levels would decrease the incidence of major CHD events in patients with CHD and low LDL levels. ${ }^{6,7}$ During a median follow-up of 5.1 years, this study demonstrated that CHD events were significantly reduced in the patients who received gemfibrozil therapy when the predominant lipid abnormality was low HDL level. The HDL-Atherosclerosis Treatment Study (HATS) also supports aspects of this finding. ${ }^{8}$ The HATS study compared simvastatin-niacin and antioxidant-vitamin therapy, alone and together or placebo, in patients with coronary disease and low plasma levels of HDL. The HATS study found that simvastatin plus niacin provided marked clinical and angiographically measurable benefits in patients with coronary disease and low HDL levels.

The 3-hydroxy-3-methylglutaryl coenzyme A reductase inhibitor regimens, commonly referred to as "statins," have become the standard treatment to achieve lower LDL concentrations. ${ }^{1,4}$ This product class has been shown to be quite effective and safe in lowering LDL levels and provides a modest improvement in HDL concentrations. ${ }^{9}$ In addition, niacin is an established product that has been demonstrated to raise HDL levels along with lowering LDL concentrations. ${ }^{10}$ However, flushing associated with immediate-release formulations of niacin has limited its adoption as a common therapy. The availability of an extended-release formulation of niacin with reduced occurrence of adverse events, along with the ATP III emphasis on the role of HDL, has renewed interest in niacin's role in improving both LDL and HDL levels. ${ }^{11-13}$ When niacin is utilized, it is often added to a statin regimen that has not achieved LDL and HDL goals as monotherapy. ${ }^{14-16}$

Simvastatin is an established statin product that has been used in several pivotal dyslipidemia studies. It has demonstrated efficacy in reducing overall deaths (0.7 relative risk), coronary deaths (0.58 relative risk), and the risk of undergoing 
TABLE 1 Lipid Changes From Baseline

\begin{tabular}{|c|c|c|}
\hline Medication & $\begin{array}{l}\text { LDL Change } \\
\text { (\% Change } \\
\text { From Baseline) }\end{array}$ & $\begin{array}{l}\text { HDL Change } \\
\text { (\% Change } \\
\text { From Baseline) }\end{array}$ \\
\hline Simvastatin $20 \mathrm{mg}^{19}$ & -38 & +8 \\
\hline Simvastatin $40 \mathrm{mg}^{19}$ & -41 & +9 \\
\hline Simvastatin $80 \mathrm{mg}^{19}$ & -47 & +8 \\
\hline $\begin{array}{l}\text { Lovastatin } 20 \mathrm{mg} / \text { extended-release } \\
\text { niacin } 500 \mathrm{mg}^{26}\end{array}$ & -25 & +11 \\
\hline $\begin{array}{l}\text { Lovastatin } 20 \mathrm{mg} / \text { extended-release } \\
\text { niacin } 1,000 \mathrm{mg}^{22}\end{array}$ & -30 & +20 \\
\hline $\begin{array}{l}\text { Lovastatin } 40 \mathrm{mg} / \text { extended-release } \\
\text { niacin } 1,000 \mathrm{mg}^{22}\end{array}$ & -36 & +20 \\
\hline $\begin{array}{l}\text { Lovastatin } 40 \mathrm{mg} / \text { extended-release } \\
\text { niacin } 1,500 \mathrm{mg}^{22}\end{array}$ & -37 & +27 \\
\hline $\begin{array}{l}\text { Lovastatin } 40 \mathrm{mg} / \text { extended-release } \\
\text { niacin } 2,000 \mathrm{mg}^{22}\end{array}$ & -42 & +30 \\
\hline
\end{tabular}

$\mathrm{LDL}=$ low-density lipoprotein cholesterol.

$\mathrm{HDL}=$ high-density lipoprotein cholesterol.

myocardial revascularization procedures (37\% reduction) as noted in the Scandinavian Simvastatin Survival Study (4S). ${ }^{17}$ The Heart Protection Study found that the addition of simvastatin reduced the rates of myocardial infarction, stroke, and revascularization procedures by about $25 \% .{ }^{18}$ In addition, the HATS study found significant beneficial effects with simvastatin plus niacin. ${ }^{8}$

The purpose of this study was to investigate the likelihood of achieving both LDL and HDL goals in the prevention of cardiovascular disease using a broad sample of U.S. residents by comparing simvastatin (Zocor) with a combined regimen of lovastatin/extended-release niacin (Advicor). An additional objective was to estimate the cost-effectiveness of each product and the incremental cost-effectiveness ratio between regimens.

\section{Methods}

\section{Overview of Models}

Decision-analytic models were created to compare the costeffectiveness between simvastatin and lovastatin/extendedrelease niacin. The perspective of the analysis was that of a health system (e.g., a managed care organization). Simvastatin was selected because it has true clinical outcomes data available with its use. Publication of the $4 S$ and HATS studies was crucial to support its inclusion in the model. The simvastatin pathway started with $20 \mathrm{mg}$ per day and was titrated monthly to a maximum dosage of $80 \mathrm{mg}$ per day. The lovastatin/extended-release niacin pathway started with $20 \mathrm{mg} / 500 \mathrm{mg}$ per day and was titrated monthly to a maximum dosage of $40 \mathrm{mg} / 2,000 \mathrm{mg}$ per day. Patients in either treatment pathway were titrated to maximum dosage unless ATP III-designated LDL and HDL targets were realized or major side effects (myopathy, liver toxicity, or major flushing) were experienced (Figure 1). Manuscripts cited in the product package labeling were used to estimate the change in cholesterol concentrations (LDL and HDL) and the frequency of clinically important adverse events with each regimen..$^{17,19-24}$

Three separate models were created for the different patient populations that required LDL goals of $<160 \mathrm{mg} / \mathrm{dL},<130$ $\mathrm{mg} / \mathrm{dL}$, or $<100 \mathrm{mg} / \mathrm{dL}$. For each decision tree, the model incorporated the titration scenarios for the changes in LDL and HDL concentrations with each dosage increase. The side-effect frequencies for each product were also included as indicated in the product labeling during the dosage titration. The model defined the effectiveness rate (i.e., successfully treated patient) as a patient achieving LDL and HDL goals and not experiencing a significant adverse event. Health care resource units and their respective costs were estimated for each pathway in the model. Cost-effectiveness was calculated by determining the directmedical costs to achieve a successfully treated patient. The decision-analytic model framework is summarized in Figure 1.

\section{Model Specifications}

Cholesterol levels for the U.S. population were obtained from the Third National Health and Nutrition Examination Survey (NHANES III) 1988-1994 adult data file, a publicly available sample of health care information for U.S. residents from the National Center for Health Statistics and the Centers for Disease Control and Prevention. ${ }^{25}$ This database was designed to provide national estimates of the health and nutritional status of the U.S.'s civilian, noninstitutionalized population. Data elements relevant to this study included patient-level data on cholesterol levels, smoking history, presence of CHD, presence of diabetes mellitus, age, and gender. These data fields were applied to the ATP III guidelines to estimate each patient's estimated 10-year CHD risk. ${ }^{4}$ Within the ATP III major risk factors (exclusive of LDL) that modify LDL goals, the only data element not included in the data set was the presence or absence of a family history of premature CHD. Following the ATP III framework, patients with $\mathrm{CHD}$ or a $\mathrm{CHD}$ risk equivalent (10-year CHD risk $>20 \%$ ) were assigned an LDL goal of $<100 \mathrm{mg} / \mathrm{dL}$. Patients with multiple ( 2 or more) risk factors and an estimated risk $\leq 20 \%$ (using the Framingham risk assessment tool) were assigned an LDL goal of $<130 \mathrm{mg} / \mathrm{dL}$; and patients with no or 1 risk factor(s) were assigned an LDL goal of $<160 \mathrm{mg} / \mathrm{dL}$. HDL goal was defined as $\geq 40 \mathrm{mg} / \mathrm{dL}$ for all patients. ${ }^{4}$ Patients were included in the model only if they had LDL levels above their calculated target goal. An HDL level less than $40 \mathrm{mg} / \mathrm{dl}$ was not used as a concomitant inclusion criterion.

The percent change in LDL and HDL at each dosing range of simvastatin or lovastatin/extended-release niacin was applied to the database to estimate the proportion of NHANES patients achieving LDL and HDL goal at each decision node (Table 1). Since no data were available in the product labeling for lovas- 


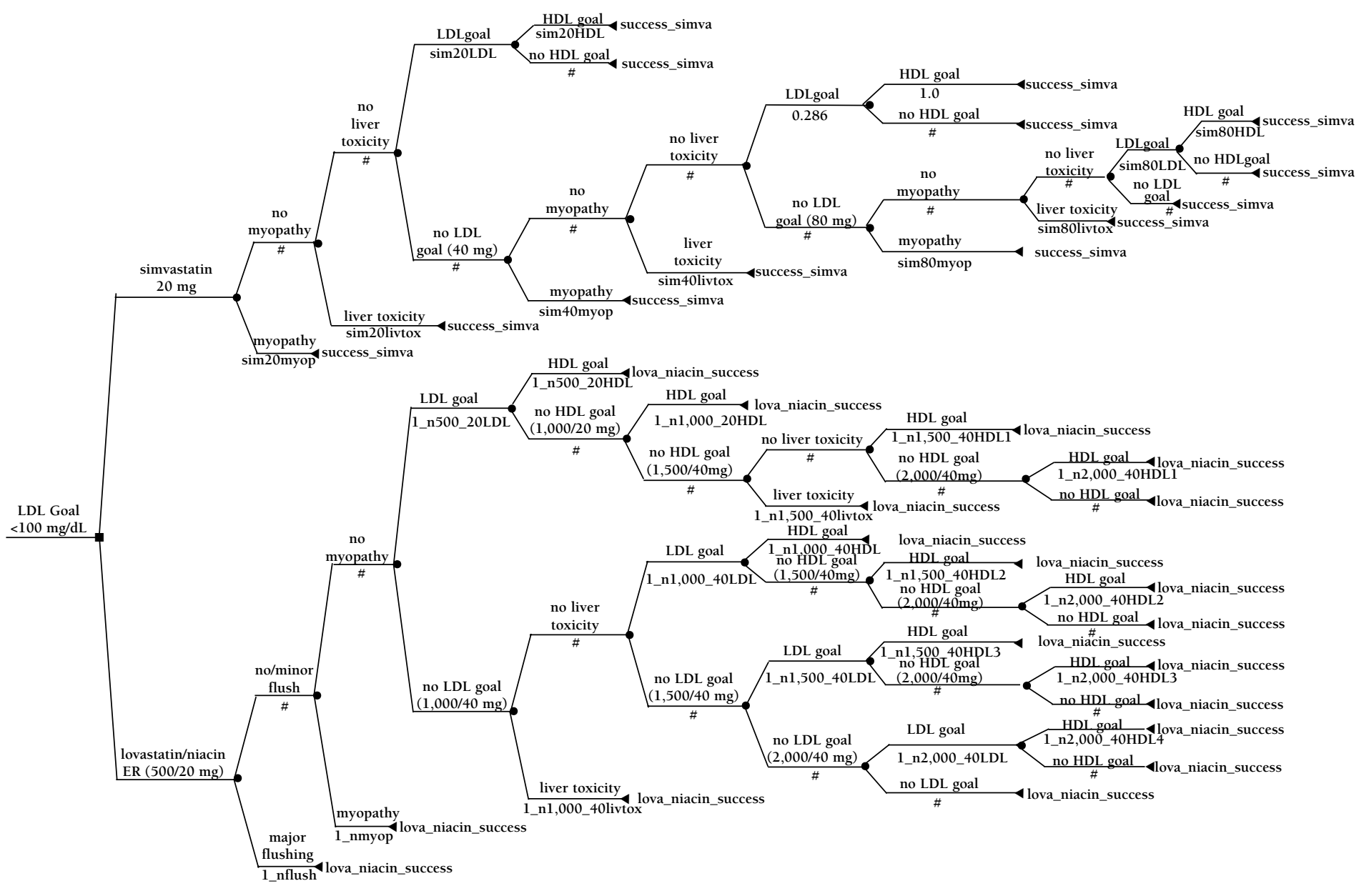

tatin/extended-release niacin $20 \mathrm{mg} / 500 \mathrm{mg}$ formulation, the results from Kashyap ${ }^{26}$ (lovastatin/extended-release niacin $10 \mathrm{mg} / 500 \mathrm{mg}$ ) were used as an estimate of cholesterol level changes. Data 3.5 software (TreeAge Software, Inc., Williamstown, MA) was used to construct the models. The time frame of the model was 4 months, assumed to be sufficient time to complete titration, if necessary. Resource units and their respective direct-medical costs to complete the titration schedule for each pathway were determined and entered into the model (Table 2). A minor problem physician visit (CPT [Current Procedural Terminology] code 99212) was assumed when no dosage change was made. A moderate/high problem physician visit (CPT code 99214) was assumed if the patient suffered an adverse event or when the dosing schedule required modification. If the patient suffered an adverse event, the medication was assumed to have been discontinued and appropri- ate laboratory tests conducted. ${ }^{16}$ This study was conducted from the perspective of a health care system. Table 2 summarizes the resource unit costs used in the analyses. Medicare's national average allowance fees were used to estimate 2002 costs associated with physician visits and laboratory tests. ${ }^{27}$ Average wholesale prices (AWP) (Medispan, fall 2002) were used to estimate medication costs. The AWP values were averaged across package size and manufacturer/relabeler. The costs calculated from the model were the estimated total health care costs (medications, physician visit costs, and laboratory costs) to use each regimen for 4 months.

Sensitivity analysis testing was conducted to determine the impact of variable uncertainty on the models. Tornado diagrams were constructed for sensitivity analysis to determine which variables produced the greatest variation in end points. (A tornado diagram is useful to identify the range of model results 


\section{TABLE 2 Resource Unit Costs Used to Populate the Decision-Analytic Model}

\begin{tabular}{|c|c|}
\hline Resource Unit (Current Procedural Terminology Code)* & Cost $(\$)$ \\
\hline Physician visit 10 minute, minor problem (99212)* & 36 \\
\hline Physician visit 25 minute, moderate/high severe (99214)* & 79 \\
\hline Lipid panel $(80061)^{*}$ & 58 \\
\hline Transaminase $(84460$ or 84450$) *$ & 19 \\
\hline Creatine kinase $(82550)^{*}$ & 25 \\
\hline Simvastatin $20 \mathrm{mg}(\mathrm{AWP})^{\dagger}$ & 4.24 \\
\hline Simvastatin $40 \mathrm{mg}(\mathrm{AWP})^{\dagger}$ & 4.30 \\
\hline Simvastatin $80 \mathrm{mg}(\mathrm{AWP})^{\dagger}$ & 4.46 \\
\hline Lovastatin $20 \mathrm{mg} /$ extended-release niacin $500 \mathrm{mg}(\mathrm{AWP})^{\dagger}$ & 1.45 \\
\hline Lovastatin $20 \mathrm{mg} /$ extended-release niacin $750 \mathrm{mg}(\mathrm{AWP})^{\dagger}$ & 1.77 \\
\hline Lovastatin 20 mg/extended-release niacin $1,000 \mathrm{mg}(\mathrm{AWP})^{\dagger}$ & 1.89 \\
\hline
\end{tabular}

TABLE 3 Baseline Demographic Characteristics of the Treatment Groups

\begin{tabular}{|c|c|c|c|}
\hline & $\begin{array}{c}\text { Goal } \\
\text { LDL }<160 \mathrm{mg} / \mathrm{dL} \\
+\mathrm{HDL} \\
\mathrm{N}=40 \mathrm{mg} / \mathrm{dL} \\
\mathrm{N}=256\end{array}$ & $\begin{array}{c}\text { Goal } \\
\text { LDL }<130 \mathrm{mg} / \mathrm{dL} \\
+\mathrm{HDL} \geq 40 \mathrm{mg} / \mathrm{dL} \\
\mathrm{N}=1,268\end{array}$ & $\begin{aligned} \text { Goal } & \\
\text { LDL } & <100 \mathrm{mg} / \mathrm{dL} \\
+\mathrm{HDL} & \geq 40 \mathrm{mg} / \mathrm{dL} \\
\mathrm{N} & =906\end{aligned}$ \\
\hline Age (mean, SD) & $61.9(14.8)$ & $41.5(15.1)$ & $65.9(13.7)$ \\
\hline Male (\%) & $92(35.9)$ & $837(66)$ & $342(37.7)$ \\
\hline $\begin{array}{l}\text { Total serum } \\
\text { cholesterol mg/dL } \\
\text { (mean, SD) }\end{array}$ & $273.7(33.9)$ & $229.1(28.5)$ & $231.9(39.0)$ \\
\hline $\begin{array}{l}\text { Serum triglycerides } \\
\mathrm{mg} / \mathrm{dL} \text { (mean, } \mathrm{SD} \text { ) }\end{array}$ & $146.4(68.9)$ & $130.6(61.0)$ & $167.3(71.8)$ \\
\hline $\begin{array}{l}\text { Serum LDL } \\
\text { cholesterol mg/dL } \\
\text { (mean, SD) }\end{array}$ & $188.7(27.7)$ & $156.2(24.2)$ & $154.4(35.3)$ \\
\hline $\begin{array}{l}\text { Serum HDL } \\
\text { cholesterol mg/dL } \\
\text { (mean, SD) }\end{array}$ & $55.7(12.9)$ & $46.7(11.9)$ & $44.0(10.6)$ \\
\hline
\end{tabular}

obtained with a series of model variables.) Since statins have been shown to have a coefficient of variation of $17 \%$ in their LDL reduction, all clinical end point variables (lipid changes and adverse events) were modified by $25 \%$ higher and lower from the point estimates in the models. ${ }^{28}$ Cost-sensitivity analyses were conducted by decreasing the medication costs by $25 \%$ for the most costly treatment strategy. In addition, sensitivity analyses were conducted to estimate cost changes over a 1-year study horizon. In the 1-year sensitivity analyses, it was assumed that there was 1 additional minor problem physician visit and 365 days of drug therapy based upon the dose for each pathway, 1 more lipid (laboratory) panel, and that previous treat- ment remained discontinued if a patient encountered a significant adverse drug event.

\section{Results}

The analysis of the NHANES data based on LDL goal stratification revealed that, among dyslipidemic persons, there were 256 patients (10.5\%) who required a goal of $<160 \mathrm{mg} / \mathrm{dL}, 1,268$ $(52.2 \%)$ patients who required a goal of $<130 \mathrm{mg} / \mathrm{dL}$, and 906 patients (37.3\%) who required a goal of $<100 \mathrm{mg} / \mathrm{dL}$. The baseline demographic characteristics of the patients are summarized in Table 3. Table 4 summarizes the success rate (i.e., proportion of patients achieving both LDL and HDL goals and not having a significant adverse event) and the cost for each regimen. It was noted that the proportion of patients achieving both LDL and HDL goals decreased with the more restrictive goal requirements for both regimens.

Figure 2 summarizes the cost-effectiveness ratios for both regimens at each treatment goal. These data demonstrate that lovastatin/extended-release niacin had lower (more favorable) cost-effectiveness ratios at each treatment LDL/HDL goal than did simvastatin.

Simvastatin had the highest clinical success rate in achieving both LDL and HDL goals in patients that required a LDL level $<160 \mathrm{mg} / \mathrm{dL}$ and a HDL $\geq 40 \mathrm{mg} / \mathrm{dL}$ (97.2\% versus $89.7 \%$ for lovastatin/extended-release niacin). However, the estimated total direct-medical cost (medications, physician visit costs, and laboratory costs) to use simvastatin was approximately twice that of lovastatin/extended-release niacin (\$665 versus \$333). Based on these estimates, the incremental cost-effectiveness ratio for each additional patient to reach LDL and HDL goals without an adverse event with simvastatin was $\$ 4,427$ when compared with lovastatin/extended-release niacin.

For both the $130 \mathrm{mg} / \mathrm{dL}$ and $100 \mathrm{mg} / \mathrm{dL}$ goal analyses, lovastatin/extended-release niacin had higher success rates than simvastatin $(85.6 \%$ versus $76.7 \%$ and $63.7 \%$ versus $60.3 \%$, respectively). In addition, for both the $130 \mathrm{mg} / \mathrm{dL}$ and $100 \mathrm{mg} / \mathrm{dL}$ goal analyses, lovastatin/extended-release niacin had lower estimated costs than simvastatin. Thus, in the incremental cost-effectiveness analyses for $130 \mathrm{mg} / \mathrm{dL}$ and $100 \mathrm{mg} / \mathrm{dL}$ LDL goal levels (plus HDL goal $\geq 40 \mathrm{mg} / \mathrm{dL}$ ), lovastatin/extended-release niacin combination therapy dominated simvastatin monotherapy.

In the $<160 \mathrm{mg} / \mathrm{dL}$ LDL and $\geq 40 \mathrm{mg} / \mathrm{dL}$ HDL goal model, sensitivity analysis demonstrated that 2 variables impacted the model success rates. Lowering the proportion of patients on simvastatin $20 \mathrm{mg}$ who reach LDL and HDL goals from 0.891 to 0.730 and 0.991 to 0.741 , respectively, lowered the overall simvastatin success rate to 0.897 . Thus, lowering the simvastatin $20 \mathrm{mg}$ lipid effects by $25 \%$ resulted in the same success rate as the baseline lovastatin/extended-release niacin. In another sensitivity analysis, when simvastatin medication costs were reduced by $25 \%$, the estimated total direct-medical cost was reduced from $\$ 665$ to $\$ 538$. This yielded an incremental cost- 
effectiveness ratio of $\$ 2,733$ for simvastatin for each additional patient to reach LDL and HDL goals without an adverse event compared with lovastatin/extended-release niacin.

For the $<130 \mathrm{mg} / \mathrm{dL}$ LDL and $\geq 40 \mathrm{mg} / \mathrm{dL}$ HDL goal model, tornado diagram sensitivity analyses suggested that the clinical success rates were most sensitive to changes in HDL levels from either $20 \mathrm{mg}$ of simvastatin or $20 \mathrm{mg} / 500 \mathrm{mg}$ of lovastatin/ extended-release niacin. When more than $86.8 \%$ of patients achieved HDL goal with simvastatin $20 \mathrm{mg}$, simvastatin was more successful than lovastatin/extended-release niacin. In the remaining sensitivity analyses, lovastatin/extended-release niacin was the most successful strategy throughout the range of other variables. When the simvastatin medication costs were reduced by $25 \%$, the estimated total direct-medical cost was reduced from $\$ 675$ to $\$ 548$. Lovastatin/extended-release niacin continued to dominate simvastatin even when the simvastatin cost was lowered by $25 \%$ and was both more successful and less costly.

For the models with goals of $<100 \mathrm{mg} / \mathrm{dL}$ LDL and $\geq 40$ $\mathrm{mg} / \mathrm{dL} \mathrm{HDL}$, tornado diagram sensitivity analyses suggested that the clinical success rates were most sensitive to the effect of simvastatin $20 \mathrm{mg}$ on HDL, the LDL reduction with lovastatin/extended-release niacin $40 \mathrm{mg} / 1,000 \mathrm{mg}$, and the LDL lowering with lovastatin-extended-release niacin $40 \mathrm{mg} / 2,000 \mathrm{mg}$. When more than $76.6 \%$ of patients achieved HDL goal with simvastatin $20 \mathrm{mg}$, simvastatin was more successful than lovastatin/extended-release niacin. In sensitivity analyses with the other variables, lovastatin/extended-release niacin remained more successful throughout the variable ranges. When the simvastatin medication costs were reduced by $25 \%$, the estimated total direct-medical cost was reduced from $\$ 773$ to $\$ 645$. Lovastatin/extended-release niacin continued to dominate simvastatin when the simvastatin cost was lowered by $25 \%$ and was both more successful and less costly.

One-year sensitivity analysis demonstrated an expansion in the estimated treatment cost differences between simvastatin and lovastatin/extended-release niacin. For the $<160 \mathrm{mg} / \mathrm{dL}$ LDL and $\geq 40 \mathrm{mg} / \mathrm{dL}$ HDL goal model, the estimated cost of simvastatin was $\$ 1,793$ compared with $\$ 792$ for lovastatin/extended-release niacin. In the $<130 \mathrm{mg} / \mathrm{dL} \mathrm{LDL}$ and $\geq 40 \mathrm{mg} / \mathrm{dL}$ HDL goal model, the estimated cost of simvastatin was $\$ 1,804$ compared with $\$ 929$ for lovastatin/extended-release niacin. With the $<100 \mathrm{mg} / \mathrm{dL}$ LDL and $\geq 40 \mathrm{mg} / \mathrm{dL}$ HDL goal model, the estimated cost of simvastatin was $\$ 1,911$ compared with $\$ 1,354$ for lovastatin/extended-release niacin. Figure 3 demonstrates the decision-tree variables with the greatest impact on treatment costs using the $<100 \mathrm{mg} / \mathrm{dL}$ LDL and $\geq 40 \mathrm{mg} / \mathrm{dL}$ HDL goal model.

For drug costs, this study used AWP costs across package size and manufacturer/relabeler. A sensitivity analysis was also conducted by assuming flat pricing across all strengths of simvastatin and was assumed to be $\$ 4.41$ per tablet. Using the $<100 \mathrm{mg} / \mathrm{dL}$ LDL and $\geq 40 \mathrm{mg} / \mathrm{dL}$ HDL goal model, the average cost of simvastatin increased from $\$ 773$ to $\$ 789$. Therefore, using flat dose
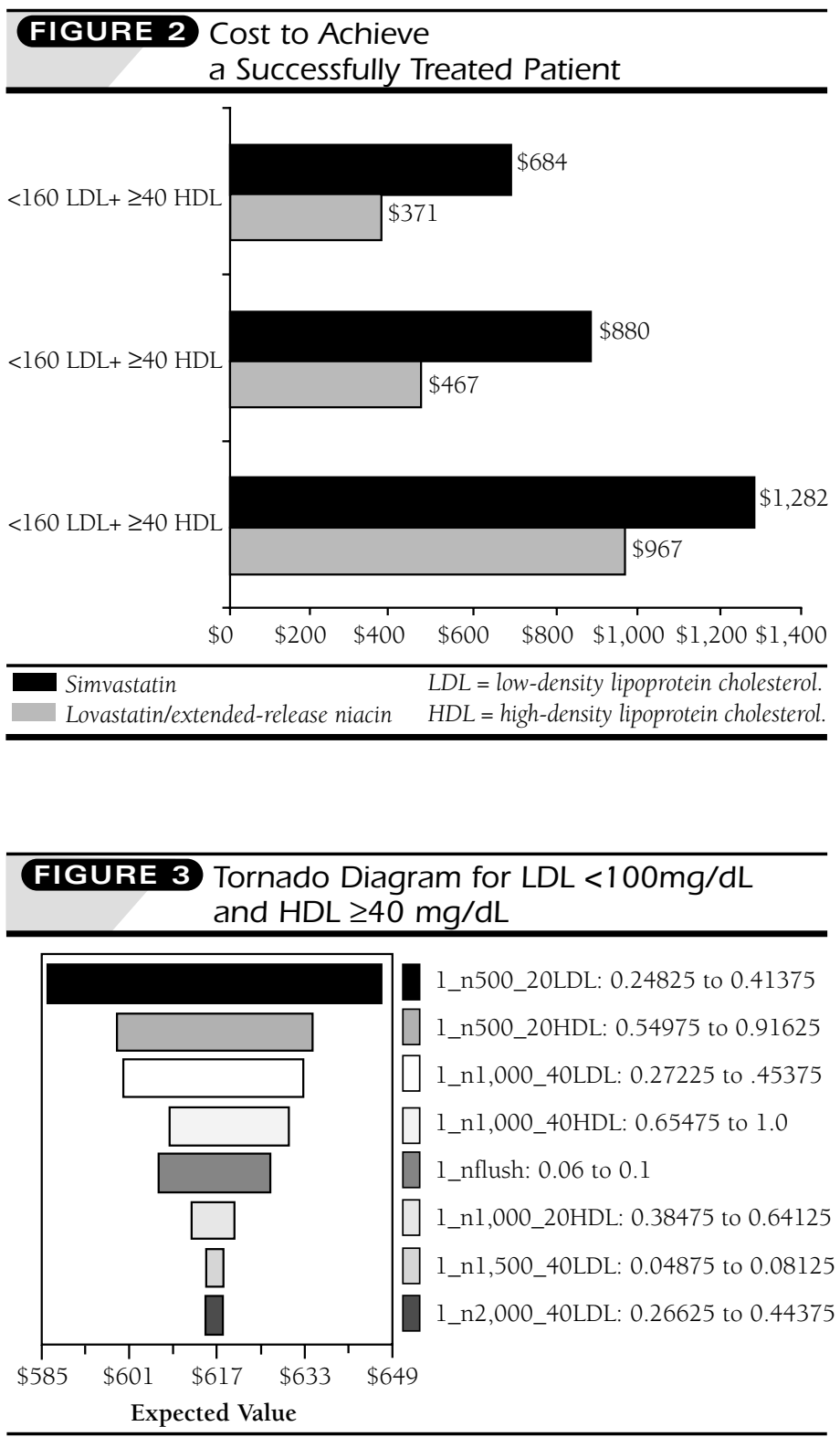

$\mathrm{LDL}=$ low-density lipoprotein cholesterol.

$\mathrm{HDL}=$ high-density lipoprotein cholesterol.

pricing did not change the rank order of the alternatives.

\section{Discussion}

The ability to achieve goal cholesterol levels has enormous implications for patients, clinicians, and health care systems. ${ }^{1,3}$ This analysis demonstrated that, in the NHANES sample, most patients with dyslipidemia require LDL goals of less than either $130 \mathrm{mg} / \mathrm{dL}$ or $100 \mathrm{mg} / \mathrm{dL}$. In targeting patient populations for LDL levels below $130 \mathrm{mg} / \mathrm{dL}$ or $100 \mathrm{mg} / \mathrm{dL}$ and $\mathrm{HDL} \geq 40 \mathrm{mg} / \mathrm{dL}$, lovastatin/extended-release niacin was both more successful and 
TABLE 4 Clinical and Cost Outcomes for Simvastatin Monotherapy and Lovastatin/Niacin Combination Therapy for Each Designated Lipid Goal

\begin{tabular}{c|c|c|c|c|c}
\hline $\begin{array}{c}\text { Goal } \\
\text { LDL + HDL } \\
\geq 40 \mathrm{mg} / \mathrm{dL}\end{array}$ & $\begin{array}{c}\text { Simvastatin } \\
\text { Success Rate (\%)* }\end{array}$ & $\begin{array}{c}\text { Simvastatin } \\
\text { Cost }(\$)\end{array}$ & $\begin{array}{c}\text { Lovastatin/ } \\
\text { Extended-Release } \\
\text { Niacin } \\
\text { Success Rate }(\%) *\end{array}$ & $\begin{array}{c}\text { Lovastatin/ } \\
\text { Extended-Release } \\
\text { Niacin } \\
\text { Cost }(\$)\end{array}$ & $\begin{array}{c}\text { Incremental } \\
\text { Cost-Effectiveness } \\
\text { Ratio }\end{array}$ \\
\hline$<160 \mathrm{mg} / \mathrm{dL}$ & 97.2 & 665 & 89 & 333 & $\begin{array}{l}\$ 4,427 \text { per additional } \\
\text { successfully treated patient }\end{array}$ \\
\hline$<130 \mathrm{mg} / \mathrm{dL}$ & 76.7 & 675 & 85.6 & 400 & $\begin{array}{l}\text { Lovastatin/ extended- } \\
\text { release niacin dominates } \\
\text { simvastatin }\end{array}$ \\
\hline$<100 \mathrm{mg} / \mathrm{dL}$ & 60.3 & 773 & 63.7 & 616 & $\begin{array}{l}\text { Lovastatin/ extended- } \\
\text { release niacin dominates } \\
\text { simvastatin }\end{array}$ \\
\hline
\end{tabular}

*Success rate is defined as a patient achieving LDL and HDL goals and not experiencing a significant adverse event. $L D L=$ low-density lipoprotein cholesterol. $\quad H D L=$ high-density lipoprotein cholesterol.

less costly than simvastatin monotherapy.

The promotion of the ATP III treatment guidelines has importantly emphasized the role of LDL levels. In addition, this guideline has encouraged an examination of HDL levels, too. The VA-HIT and HATS studies suggest that patients may benefit from optimization of both LDL and HDL levels. ${ }^{6,7}$ Further research is needed to examine whether these long-term benefits are also observed with lovastatin/extended-release niacin.

The 3 decision-analytic models demonstrate that both treatment regimens had fewer patients achieve LDL and HDL goals as the goals became more restrictive. These results also indicate that the short-term direct-medical costs are larger, regardless of regimen, to achieve tighter lipid control. Long-term studies are needed to determine the clinical and economic outcomes with the goals being applied following publication of the ATP III guidelines.

These data are consistent with research from other investigators. Statins are highly regarded treatments and considered cost effective in the treatment of both secondary and primary prevention of dyslipidemia. ${ }^{29-40}$ Numerous evaluations have been conducted that support the important role of these products..$^{41-45}$ In addition, based on the VA-HIT trial, treatment with gemfibrozil to raise low HDL levels has been shown to be quite cost effective. ${ }^{46}$ The complementary nature of extended-release niacin in combination with statin treatment has also been demonstrated. ${ }^{14-15}$ The data from this study support the rationale of using extended-release niacin in combination with statins. The formulation evaluated in this study (lovastatin/extendedrelease niacin) appears to be a cost-effective treatment alternative to simvastatin monotherapy in the majority of patients.

Although simvastatin had the highest success rate for the $\mathrm{LDL}<160 \mathrm{mg} / \mathrm{dL}$ and $\mathrm{HDL} \geq 40 \mathrm{mg} / \mathrm{dL}$ goal levels, this regimen had a total direct-medical cost almost twice that of lovastatin/extended-release niacin. The explanation for this observation appears to be the pricing of simvastatin that is the same regardless of dose for the $20 \mathrm{mg}, 40 \mathrm{mg}$, and $80 \mathrm{mg}$ doses (Table 2; the AWPs for the $5 \mathrm{mg}$ and $10 \mathrm{mg}$ doses of simvastatin are lower than the 3 doses studied in this research). Although not often recommended, the practice of splitting the tablets of higher-dose simvastatin tablets would partially offset simvastatin's higher unit $\operatorname{cost}^{47}$; splitting the $80 \mathrm{mg}$ dose would reduce the $40 \mathrm{mg}$ per day cost by $50 \%$.

There are several important limitations that should be kept in mind when interpreting this study. Since no data were available in the product labeling for lovastatin/extended-release niacin $20 \mathrm{mg} / 500 \mathrm{mg}$ formulation, the results from Kashyap ${ }^{26}$ lovastatin/extended-release niacin $10 \mathrm{mg} / 500 \mathrm{mg}$ were used as an estimate of cholesterol-level changes. Therefore, the model likely understimated the number of patients reaching LDL and HDL goals at this dosage.

When incorporating medication costs, this study used AWP values. In a market economy with negotiated contract prices, actual purchase costs may be lower than AWP but would be similarly discounted across the products studied in this research. In addition, health systems may receive rebates from pharmaceutical manufacturers that would further lower the medication resource unit costs. Since contracts and rebates are confidential and variable by health system, this study relied upon AWP, a reasonable cost basis for this research since none of the products studied are available by generic name. In addition, the costs for statins may be expected to decrease in the future as additional products become available generically. ${ }^{48}$

Another limitation with this study is the inability to account for variation in a patient's recommended lipid diet. Since diet can 
independently impact cholesterol levels, this analysis was unable to incorporate this possible variability. A patient who is noncompliant with a recommended diet would be anticipated to have inferior lipid changes that are predicted with this model.

The basis of this study was that the NHANES III database was representative of the U.S. population. In addition, the effectiveness analysis in this study was based on the lipid changes in the product labeling for simvastatin and lovastatin/extendedrelease niacin. Lipid changes in actual practice may vary from those stated in the product labeling. Furthermore, this study used assumptions concerning the number of physician visits and laboratory tests needed to complete the titration schedules for both products. Actual practice patterns may vary between clinicians and health plans. The significant flushing rate with lovastatin/extended-release niacin was assumed to be a treatment failure in all cases and lowered the overall effectiveness for this product. In practice, it is possible that some patients may have tolerated the product with a slower titration schedule and/or administration of aspirin.

\section{Conclusion}

Both simvastatin and lovastatin/extended-release niacin are important agents to attain both LDL and HDL goals. This study demonstrated that simvastatin was more successful in achieving an LDL goal $<160 \mathrm{mg} / \mathrm{dL}$ and an HDL goal $\geq 40 \mathrm{mg} / \mathrm{dL}$. However, only a minority of patients requires this goal. The NHANES data demonstrate that the majority of U.S. residents require an LDL goal of $<100 \mathrm{mg} / \mathrm{dL}$ or $<130 \mathrm{mg} / \mathrm{dL}$. For both of these goals—and the desired end point of HDL $\geq 40 \mathrm{mg} / \mathrm{dL}-$ lovastatin/extended-release niacin was both more successful and less costly than simvastatin.

\section{DISCLOSURES}

Funding for this study was provided as a grant to the University of Arizona by Kos Pharmaceuticals and was obtained by authors Edward P. Armstrong, Woodie M. Zachry III, and Daniel C. Malone. Armstrong and Malone are employed by the University of Arizona, and Zachry was employed by the university at the time of this study. Armstrong attended 2 Kos Pharmaceuticals Advisory Boards and received honoraria from Kos; all authors received grant support from Kos. Armstrong served as principal author of the study. Study concept and design, analysis and interpretation of data, and statistical expertise were contributed by all authors. Drafting of the manuscript was primarily the work of Armstrong, and its critical revision was the work of Zachry and Malone.

\section{REFERENCES}

1. McKenney JM. New cholesterol guidelines, new treatment challenges. Pharmacotherapy. 2002;22:853-63.

2. Irons BK, Snella KA, McCall K, MacLaughlin EJ, Villarreal M. Update on the management of dyslipidemia. Am J Health Syst Pharm. 2002;59:1615-25.

3. Talbert RL. New therapeutic options in the National Cholesterol Education Program Adult Treatment Panel III. Am J Manag Care. 2002;8:S301-S307.

4. Expert Panel on Detection, Evaluation, and Treatment of High Blood Cholesterol in Adults. Executive summary of the Third Report of the National
Cholesterol Education Program (NCEP) Expert Panel on Detection, Evaluation, and Treatment of High Blood Cholesterol in Adults (Adult Treatment Panel III). JAMA. 2001;285:2486-97.

5. Koeller J, Talbert RL. Modification of high-density lipoprotein cholesterol in the management of cardiovascular risk. Pharmacotherapy. 2002;22:1266-77.

6. Robins SJ, Collins D, Wittes JT, et al. Relation of gemfibrozil treatment and lipid levels with major coronary events. VA-HIT: a randomized controlled trial. JAMA. 2001;285:1585-91.

7. Rubins HB, Robins SJ, Collins D, et al. Gemfibrozil for the secondary prevention of coronary heart disease in men with low levels of high-density lipoprotein cholesterol. N Engl J Med. 1999;341:410-18.

8. Brown BG, Zhao XQ, Chait A, et al. Simvastatin and niacin, antioxidant vitamins, or the combination for the prevention of coronary disease. N Engl J Med. 2001;345:1583-92.

9. Pedersen TR, Berg K, Cook TJ, et al. Safety and tolerability of cholesterol lowering with simvastatin during 5 years in the Scandinavian Simvastatin Survival Study. Arch Intern Med. 1996;156:2085-92.

10. Ito MK. Niacin-based therapy for dyslipidemia: past evidence and future advances. Am J Manag Care. 2002;8:S315-S322.

11. Knopp RH, Alagona P, Davidson M, et al. Equivalent efficacy of a timerelease form of niacin (Niaspan) given once-a-night versus plain niacin in the management of hyperlipidemia. Metabolism. 1998;47:1097-1104.

12. Grundy SM, Vega GL, McGovern ME, et al. Efficacy, safety, and tolerability of once-daily niacin for the treatment of dyslipidemia associated with type 2 diabetes. Arch Intern Med. 2002;162:1568-76.

13. Pieper JA. Understanding niacin formulations. Am J Manag Care. 2002;8: S308-S314.

14. Wolfe ML, Vartanian SF, Ross JL, et al. Safety and effectiveness of Niaspan when added sequentially to a statin for treatment of dyslipidemia. Am J Cardiol. 2001;87:476-79.

15. Taher TH, Dzavik V, Reteff EM, et al. Tolerability of statin-fibrate and statin-niacin combination therapy in dyslipidemic patients at high risk for cardiovascular events. Am J Cardiol. 2002;89:390-94.

16. Olson BM, Malone DC. Modeling the cost-effectiveness of doubling atorvastatin's dose versus adding niacin ER. Formulary. 2001;36:730-46.

17. Scandinavian Simvastatin Survival Study Group. Randomised trial of cholesterol lowering in 4,444 patients with coronary heart disease: the Scandinavian Simvastatin Survival Study (4S). Lancet. 1994;344:1383-89.

18. Heart Protection Study Collaborative Group. MRC/BHF heart protection study of cholesterol lowering with simvastatin in 20,536 high-risk individuals: a randomised placebo-controlled trial. Lancet. 2002;360:7-22.

19. Hunninghake DB, McGovern ME, Koren M, et al. A dose-ranging study of a new, once-daily, dual-component drug product containing niacin extendedrelease and lovastatin. Clin Cardiol. 2003;26:112-18.

20. Walker JF, Tobert JA. The clinical efficacy and safety of lovastatin and MK-733-an overview. European Heart J. 1987;8(suppl E):93-96.

21. Zocor [package insert]. Whitehouse Station, NJ: Merck \& Co., Inc.; May 2002.

22. Advicor [package insert]. Miami, FL: Kos Pharmaceuticals, Inc.; November 2001

23. Mevacor [package insert]. Whitehouse Station, NJ: Merck \& Co., Inc.; April 2001

24. Niaspan [package insert]. Miami, FL: Kos Pharmaceuticals, Inc.; November 1999

25. Third National Health and Nutrition Examination Survey (NHANES) adult data file 1988-1994 (Catalog Number 77560), National Center for Health Statistics and the Centers for Disease Control and Prevention. Available at: http://www.cdc.gov/nchswww/nchshome.htm. Accessed December 15, 2003.

26. Kashyap ML, McGovern ME, Berra K, et al. Long-term safety and efficacy of a once-daily niacin/lovastatin formulation for patients with dyslipidemia. Am J Cardiol. 2002;89:672-78. 
27. Health Care Consultants 2002. Physicians Fee \& Coding Guide. Augusta, GA: Health Care Consultants of America, Inc.; 2002.

28. Downs JR, Clearfield M, Weis S, et al. Primary prevention of acute coronary events with lovastatin in men and women with average cholesterol levels. Results of AFCAPS/TexCAPS. JAMA. 1998;279:1615-22.

29. Ganz DA, Kuntz KM, Jacobson GA, Avorn J. Cost-effectiveness of 3-hydroxy-3-methylglutaryl coenzyme A reductase inhibitor therapy in older patients with myocardial infarction. Ann Intern Med. 2000;132:780-87.

30. Caro J, Klittich W, McGuire A, et al. The West of Scotland Coronary Prevention Study: economic benefit analysis of primary prevention with pravastatin. BMJ. 1997;315:1577-82.

31. Elliott WJ, Weir DR. Comparative cost-effectiveness of HMG-CoA reductase inhibitors in secondary prevention of acute myocardial infarction. Am J Health Syst Pharm. 1999;56:1726-32.

32. Huse DM, Russell MW, Miller JD, et al. Cost-effectiveness of statins. Am J Cardiol. 1998;82:1357-63

33. Koren MJ, Smith DG, Hunninghake DB, et al. The cost of reaching national cholesterol education program (NCEP) goals in hypercholesterolaemic patients. A comparison of atorvastatin, simvastatin, lovastatin and fluvastatin. Pharmacoeconomics. 1998;14:59-70.

34. Prosser LA, Stinnett AA, Goldman PA, et al. Cost-effectiveness of cholesterol-lowering therapies according to selected patient characteristics. Ann Intern Med. 2000;132:769-79.

35. Hay JW, Yu WM, Ashraf T. Pharmacoeconomics of lipid-lowering agents for primary and secondary prevention of coronary artery disease.

Pharmacoeconomics. 1999; 1:47-74.

36. Hilleman DE, Heineman SM, Foral PA. Pharmacoeconomic assessment of HMG-CoA reductase inhibitor therapy: an analysis based on the CURVES study. Pharmacotherapy. 2000;20:819-22.

37. Hilleman DE, Phillips JO, Mohiuddin SM, Ryschon KL, Pedersen CA. A population-based treat-to-target pharmacoeconomic analysis of HMG-CoA reductase inhibitors in hypercholesterolemia. Clin Ther. 1999;21:536-62.
38. Goldman L, Weinstein MC, Goldman PA, Williams LW. Cost-effectiveness of HMG-CoA reductase inhibition for primary and secondary prevention of coronary heart disease. JAMA. 1991;265:1145-51.

39. Hay JW, Wittels EH, Gotto Jr. AM. An economic evaluation of lovastatin for cholesterol lowering and coronary artery disease reduction. Am J Cardiol. 1991;67:789-96

40. Ashraf T, Hay JW, Pitt B, et al. Cost-effectiveness of pravastatin in secondary prevention of coronary artery disease. Am J Cardiol. 1996;78:409-14.

41. Johannesson M, Jonsson B, Kjekshus J, et al. Cost-effectiveness of simvastatin treatment to lower cholesterol levels in patients with coronary heart disease. N Engl J Med. 1997;336:332-36.

42. Grover SA, Coupal L, Paquet S, Zowall H. Cost-effectiveness of 3-hydroxy-e-methylglutaryl-coenzyme A reductase inhibitors in the secondary prevenion of cardiovascular disease. Arch Intern Med. 1999;159:593-600.

43. McKenney JM. The cost of treating dyslipidaemia using national cholesterol education program (NCEP) guidelines. Pharmacoeconomics. 1998;14 (suppl 3):19-28.

44. Jacobson TA, Schein JR, Williamson A, Ballantyne CM. Maximizing the cost-effectiveness of lipid-lowering therapy. Arch Intern Med. 1998;158:197789.

45. Jackson JD. Economics and cost-effectiveness in evaluating the value of cardiovascular therapy: lipid-lowering therapies—an industry perspective. Am Heart J. 1999;137:S105-S110.

46. Nyman JA, Martinson MS, Nelson D, et al. Cost-effectiveness of gemfibrozil for coronary heart disease patients with low levels of high-density lipoprotein cholesterol. Arch Intern Med. 2002;162:177-82.

47. Gee M, Hasson NK, Hahn T, Ryono R. Effects of a tablet-splitting program in patients taking HMG-CoA reductase inhibitors: analysis of clinical effects, patient satisfaction, compliance, and cost avoidance. J Manag Care Pharm. 2002;6:453-58.

48. Hay JW. Evaluating the cost-effectiveness of statins. J Manag Care Pharm. 2004;10:569-71. 